\title{
The Causes Analysis of Public Policy Implementation Deviation: Based on a Framework of Paul A. Sabatier and Daniel A. Mazmanian
}

\author{
Qing $\mathrm{Xu}^{\mathrm{a}}$, Lili Gao ${ }^{\mathrm{b} *}$ \\ School of Government, Beijing Normal University, Beijing 100875, China

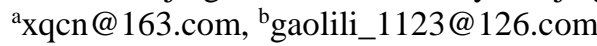

\begin{abstract}
Based on the framework of Paul A. Sabatier and Daniel A. Mazmanian, we analyse the causes of public policy implementation deviation in China. By theoretical analysis and system analysis, we begin with the manifestations of policy implementation deviation. They include: (1) perfunctory policy implementation, (2) attached policy implementation, (3) alternative policy implementation, (4) delaying policy implementation and (5) rough policy implementation. Then we discuss main causes of public policy implementation deviation. Two aspects of policy, both policy itself and variables except policy, could be responsible for the deviation of public policy. And there are many indicators below these two aspects. These indicators must be given top priority. We conclude the paper with some advice based on above causes of policy implementation deviation. The major advice include: (1) improve policy itself, such as formulate policy that have incorporation of adequate causal, make clear policy directives; allocate the financial and administrative rights of central government and local governments properly; (2) ameliorate variables except policy, such as control the development of interest groups; make disadvantaged groups express their demands more easily; optimize the supervision mechanism of the public policy implementation.
\end{abstract}

Keywords-The causes of public policy implementation deviation; A framework of Paul A. Sabatier and Daniel A. Mazmanian

\section{INTRODUCTION}

From the mid to late 1990s, Chinese scholars give top priority to the research on public policy implementation, and a batch of excellent research results have already been produced Chinese scholars, Huang Ding, Yuejin Jing, Xianglin Xu, Zhenming Chen, etc, were engaged in the study of public policy implementation earlier and systematically. By consulting relevant literature, the research of the causes of public policy implementation deviation has been studied more and more extensively. However, few scholars have analysed the reasons of public policy implementation deviation based on the framework of prof. Paul A. Sabatier and prof. Daniel A. Mazmanian. Therefore, we shall base on that framework to analyse the causes of public policy implementation deviation.
In the remainder of this article, there are four sections: the manifestations of implementation deviation, the causes of these different manifestations, the countermeasures of prevention and remedy of those deviations and conclusion.

\section{THE MANIFESTATIONS OF PUBLIC POLICY IMPLEMENTATION DEVIATION}

The phenomenon of public policy implementation is very common in the process of public policy implementation. There are many factors that lead policy to deviate from policy goals. The process that governments transform the public policy of text form or government discourse system into the realistic policy objectives is not a straight line process. From the central government to the local government, the policy objectives always experience the process of police refinement or replanning. There is some distance between each government level from policy formulation to policy implementation. The distance gives a chance to the distortion of policy goals are in the transmission process. Then, there are some deviations in a series of policy processes [1]. The public policy implementation deviation is paid due attention by three generations of policy implementation researchers. It is mainly included in five aspects: (1) The deviation of perfunctory implementation; (2) The deviation of policy attached implementation; (3) The deviation of policy alternative implementation; (4) The deviation of delaying implementation; (5) The deviation of rough implementation.

\section{A. The deviation of perfunctory policy}

The deviation of perfunctory implementation refers that direct or indirect implementing subjects only make calls or take enforcement measures symbolically in the process of public policy implementation. They perform their duty in a perfunctory manner. Slackness can also appear in the quality of work. Furthermore, they may agree overtly but oppose covertly. The progress of policy implementation is stayed at the propaganda and expression of policy. When this situation continues, the implementation of public policy is in the form, the policies do not play a part, and the authority and seriousness of public policy must be affected. 


\section{B. The deviation of attached policy}

The deviation of policy attached implementation refers that direct or indirect implementing subjects usually attach some contents to the original policy in the process of public policy implementation. These contents are always beneficial to individual interests or local interests. What's more, they use the combination of principle and flexibility of policy implementation as an excuse to rationalize its additional behaviour. Policy attached implementation is under the signboard of the implementation that combined with the actual situation. The attached policy implementation changes the target, scope, and objectives which the policy wants to adjust and control, etc. When this situation continues, public policy implementation must be hindered.

\section{The deviation of alternative policy}

The deviation of alternative policy implementation refers that the policy consistent with the original policy on the surface, but actually deviated from it in the process of public policy implementation. Some direct or indirect implementing subjects misinterpret policy contents deliberately. Those policy contents are explained in line with the interests of the region, the department or its own. In essence, alternative policy implementation violates the original plan of policy implementation. Those policies are as if they appear united outwardly but divided at heart, or as if they steal the beams and pillars and replace them with rotten timbers. When this situation continues, the public policy goals and public interests can't come true.

\section{The deviation of delaying implementation}

The deviation of alternative policy implementation refers that direct or indirect implementing subjects miss the best time for policy enforcement in the process of public policy implementation, because they fail to take action in time. It leads the situation that the public policy goals and public interests can't come true. Public policy implementation has a strong timeliness. The effectiveness of policy enforcement must be affected beyond the time limit.

\section{E. The deviation of rough implementation}

The deviation of rough implementation refers that direct or indirect implementing subjects do not comply with procedures and regulations. They take coercive orders, even turn into personal attack and other extreme measures. Some public policies are implemented on the violation of laws and regulations. The rough implementation not only damages the image of government, but also reduces the authority of policy enforcement. When this situation continues, policy objects will resist the implementation of public policy. The contradiction between executing subjects and policy objects is intensified, which reduces the execution force of public policy.

\section{ANALYSIS OF THE CAUSES OF PUBLIC POLICY IMPLEMENTATION DEVIATION}

There are many manifestations of public policy implementation deviation. The reasons are also complex. Next, use the framework of Paul A. Sabatier and Daniel A. Mazmanian to analyse the reasons for public policy implementation deviation. The two aspects of analysis mainly include policy itself and variables except policy.

In 1979, American policy scientists, Paul A. Sabatier and Daniel A. Mazmanian, publish "The Implementation of Regulatory Policy: A Framework of Analysis" in the "Policy Studies Journal". They put forward a framework to analyse public policy implementation. The framework is comprehensive. They argue that the key to public policy implementation is to identify the factors which affect the achievement of statutory objectives throughout this entire process. These can be divided into three categories: (1) the tractability of the problems being addressed by the statute; (2) the ability of the statute to favorably structure the implementation process; (3) the net effect of a variety of "political" variables on the balance of support for statutory objectives [2]. Sabatier and Mazmanian analysed the crucial factors of public policy implementation from above three aspects. Then, that divided these three aspects into several small indicators under each category. Public policy implementation can be influenced by working together of these factors. The framework of Paul A. Sabatier and Daniel A Mazmanian is shown as follow [3]. 


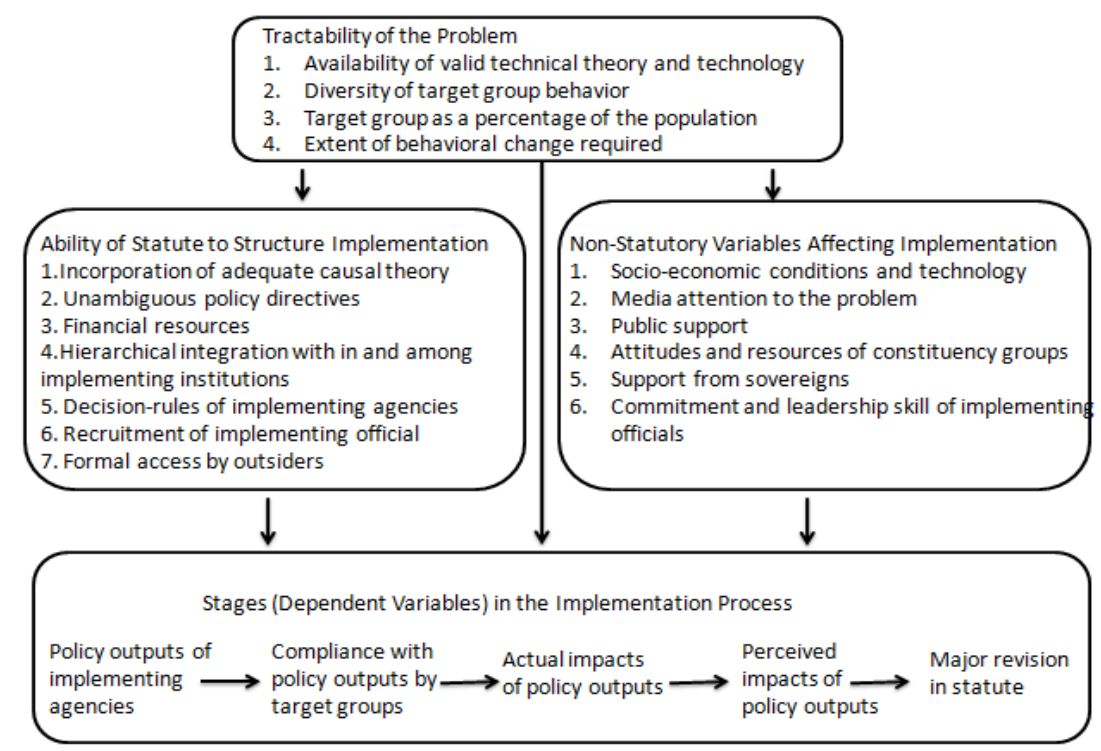

Fig. 1. Skeletal Flow Diagram of the Variables Involved in the Implementation Process

\section{A. The causes of policy itself}

\section{1) The policy itself is unreasonable}

The policy itself should have incorporation of adequate causal. There is close relationship between the effectiveness, scientificity, rationality and validity of policy itself. If policy itself is not rational, and not aimed at an object fact, then the public policy implementation will be obstructed, even will not be enforced at all.

\section{2) Ambiguous policy directives}

A vague policy is not a bad thing. Under the uncertain environment and unexperienced condition, a policy that leaves room has great flexibility. Then the detail of policy can be easily changed to suit a different situation. Furthermore, it is helpful to mobilize the initiative of the government at a lower level, the government will have the ability and take delight in deciding to what to do next and to do it, without needing other people to tell them what to do. At the same time, in case decision-making is wrong, the authority of the central government can be protected [4]. However, ambiguous policy directives may cause a lot of trouble, implementers fail to understand policy properly, even lead to delaying policy implementation, public policy do not be implemented immediately or at the planned or expected time, but it be left until later. The government should stipulate a set of clear and consistent plans, objects and procedures. Unambiguous policy is one of the important prerequisites of effective policy enforcement, it is also the basis of the action of policy implementation. Policy implementation involves multiple administrative organizations. If administrative organizations have different understanding of policy content, then the policy implementation will be more difficult.

\section{3) Inadequate financial resources}

No matter how specific the policy is, the organization and personnel who is responsible for policy implementation have inadequate financial resources, the outcome of the policy implementation cannot achieve the stated goals of the policy. All policy implementation is needed appropriate amount of human, material and financial resources. With fiscal decentralization, central government and local government lack of norm. The purview division between provincial government and sub- provincial government is much more unclear. For the sake of their own interests, many direct and indirect implementing subjects always handle affairs according to their own will, they are lack of coordination and ignore whole situation, they even deceive and confront central government, these lead to a situation that the intention of the policy changes, public policy implementation deviate, particularly policy alternative, policy attached. Moreover, after the reform of tax-sharing, what are the property rights for province, municipality and county? Which administrative power should they be responsible for? There is no explicitly stipulated. As a result, there is a lot of wrangling between all levels of governments. The public finance revenue of villages and towns includes extra budgetary funds and lawfully raised funds, then, in order to increase revenue, they focus on take advantage of lawfully raised funds, such as productive investment, but ignore the development of public services. It leads public policy implementation deviation under the fiscal revenue expansion condition. At the same time, grassroots governments are more concerned about their own interests, they aim for the growth of their own revenue. Therefore, they implement national policy conditionally. On the one hand, they would like to implement some policies in their favour actively; on the other hand, they would not like to implement other policy against them. In consequence, the efficiency and quality of public policy implementation can't be guaranteed and public policy implementation deviation is inevitable. 
4) Hierarchical integration within and among implementing institutions is incoordination

In the process of public policy implementation, there is a lack of good communication between implementing subjects and implementing objects, therefore, implementing objects may question the policy, in additional, because the opinions and suggestions of implementing objects and information feedback is not in time, the policy implementation deviation can't be corrected in time, as a result, the effective implementation of the policy has been affected. Local governments under pressure systems are not passive political actors. They have their own interests independently and adjust their direction or choose resistance [5]. The process of public policy implementation always involve more than one department or agency. If police enforcement rights are uncoordinated and undefined in various departments and agencies, then each departments and agencies will fight for their own benefit, and play down their responsibilities after making mistakes. It leads some policy implementing subjects diverge and create a distortion of the target when they enforce them. Furthermore, in the process of public policy implementation, there may be some phenomenon of fighting both with open and secret means. When this situation continues, it is not conductive to the unity of all departments, but weakening institutional cohesion. Moreover, some departments may try to pass the buck. They refuse to accept responsibility and say someone else is responsible. It leads a situation that it is difficult for implementing subjects to implement public policy implementation.

In china, the major problems arise in this area as follows: the central government and local governments lack coordination; among departments within the same level of government lack coordination; for the benefit of their own, the local governments lack coordination, it leads to the phenomenon of local protectionism. Because among implementing subjects lack of coordination and communication, additionally, the functions of all implementing subjects are unclear, intersect, overlap and dislocation, it can lead a mess situation that some implementing subjects pass the buck, blame each other, they are multiple execution and even cause the policy implementation to interrupt and stop. As a consequence, the negative impact of policy implementation is enormous.

\section{5) Imperfect decision-rules of implementing agencies}

The procedure justice of public policy is imperfect. The public interest is the criterion to judge whether the government's behaviour is proper or inappropriate. Because of some reasons, there is a possibility that public officials have degenerated public right into personal gain. As a result, some inhibiting procedures should be set in order to limit the operation of public rights. The procedure justice of public policy must be met four requirements as follow: citizen participation and policy decision; citizenship is equal in the process of procedure; value neutrality in the decision-making process; autonomy of the decision-making process. In a word, the more explicit, rational and scientific decision-making procedures are, the more conducive to the policy implementation.
6) Inappropriate recruitment of implementing official

Policy implementation always rely on a certain number of staff. As a result, the effect of policy implementation will be influenced by the quality of the executive. Highly professional executives will actively implement policies and will be working to ensure those policies are implemented effectively, however, Less qualified and irresponsible executives can be perfunctory, leading to a failure of policy implementation. So the qualifications of executive are one of the main factors of policy implementation, such as professional knowledge, basic skill, high responsibility and reliability. Firstly, some executives lack of professional knowledge, they are unable to grasp the spiritual connotation and practical requirements of the policy accurately. Social problems are complex and changeable. The effective policy implementation requires that the executive must have a solid theoretical foundation and comprehensive analysis capability. It is hard to grasp the spirit of policy when the executive's knowledge reserves are insufficient. If the integrity and detail of policy are misunderstood, public policy implementation will deviate. Secondly, the moral quality of executives is not high. Public policy serves the public. If an executive does not even have awareness for the service, they are unable to overcome the difficulties in the process of policy implementation, it will be possible for them to give up halfway. When this situation continues, the effective implementation will not come true. Hence it is of great significance to optimize the moral quality of the executives. Last but not least, the public policy implementation must involve the interests. When regional interests conflict with personal interest, if some executives does not face the problem fairly and objectively, but motivated by interests, the public policy enforcement will be prone to crisis, even deviate from policy goals

\section{7) Inadequate formal access by outsiders}

The number of outsiders's participation will affect the public policy implementation. Currently, citizens' participation in institutional (system) channel is inadequate in China. In China, citizen participation in institutional channel mainly includes the following aspects: firstly, participate in the basic social system such as the People's Congress and the Political Consultative Conference; secondly, participation in the policy process by electing people's representatives and recommending members of the Political Consultative Conference ; last but not least, through various forms of organization, citizens can also participate indirectly in the formulation and implementation of public policies. These institutional channels provide fundamental guarantee for citizen's participation in public policy implementation. However, these systems are imperfect. Some rules are too abstract. The system is not sound enough to guarantee citizens' participation in public policy. Moreover, the system of public policy implementation is also relatively closed. The citizens' institutional (system) channel is relatively few and blocked. It is hard to meet the growing demand of citizens' participation. Furthermore, because the interaction between governments and citizens is blocked, citizens lack of necessary information of participation, both citizens and policy executives are always in the situation of information asymmetry. Although the interaction between governments and citizens is a reality in public policy implementation in 
China, this mechanism is just a formality. It is difficult for citizens to participate in public policy implementation, because there is lack of guarantee of legitimacy and adequate means of civic engagement and necessary right.

\section{B. The causes of variables except policy}

1) Imperfect Socio-economic conditions and technology

No matter which public policy is implemented, it will be influenced by its current environment, such as political environment, economic environment and social environment. As Hood said, "The choice of policy tools is not a kind of technical operation, but a religious or political affair" [6]. A good environment can promote public policy implementation. In contrast, public policy implementation must be delayed in the bad circumstances. The political system determines the nature of social classes and organization form of public policy implementation in China. The state body is the most basic political system in the country. It embodies the nature of social classes. A kind of state body requires corresponding public policy and implementation of social classes nature. At the same time, the political system also determines the composition of executive organization and the way of public policy implementation. Moreover, economic conditions also constrain the public policy implementation. The economic base determines the superstructure. The low level of the GDP of a country or region means that the soil is not fertile enough for public policy implementation. When this situation continues, it is difficult to ensure that policy is properly implemented. In short, the better the economy is, the better the implementation of public policy is. Many factors may affect the application of policy tools, such as political, economic and social environment, actuators' motivation, attitudes and value pursuit of the policy implementer.

\section{2) Incontinuous media attention to the problem}

There is close relationship and interaction between public policy and public opinion. The dynamic relationship between them is linked by media which is an important bridge. Comparative study of public policy shows that media reports have a significant impact on public opinion. The media reports influence the whole process of public policy formulation, decision-making and implementation. As a consequence, the study of public media is conductive to the construction of benign interaction between public policy and public opinion. It is of great value to promote the scientization and democratization of government decision-making.

\section{3) Inadequate public support}

The public is also a subject of public policy implementation. The implementation of public policy requires close cooperation between politicians and the affected subjects. If public support for public policy is inadequate, the effect of the policy implementation will be greatly weakened and the cost will be greatly increased.

\section{4) The tough attitude of interest groups}

Interest groups play an important role in the public policy implementation. They can achieve their goals by many ways, such as their social network, public opinion, persuasion, and expert advisory groups. When a public policy implementation impairs the interests of a particular Interest group, it will inevitably choose to implement negatively or resist implementing the public policy. Different interest groups may have different interests, intentions and traditions. All of them can hinder the public policy implementation and affect the effect of the enforcement of public policy. To some extent, Interest groups distort and hinder the process of reform in China. It also influences the function of public rights and increases the cost of public policy. Furthermore, it influences the efficiency and authority of public policy. Social inequality will be exacerbated and it is not conductive to social stability. When this situation continues, Rent-seeking and corruption will be common phenomenon and the public interest will be damaged.

\section{5) Insufficient support from supervising organ}

Insufficient supervision for implementing subjects should be paid due attention. There is close relationship between the implementation of public policy and the use of power. Too much power inevitably leads lead to abuse. Therefore, it is necessary to establish a scientific and effective supervision mechanism: the supervision between superior and subordinate and between colleagues at the same level. In addition, the supervision for policy implementation should also be paid due attention. For local governments, firstly, the central government should supervise the status of policy implementation; secondly, there should also be supervision of Local People's Congresses at the same level of local governments; last but not least, the supervision of the people is necessary and indispensable. Although a diversified supervision has formed in China, the effect of supervision is not ideal. Because supervision organizations lack of independence, and the responsibility of each supervision organization is unclear, the effect of supervision is not very effective. It leads to the disorder of supervision, such as everyone is supervising and everyone is not supervising. Furthermore, some supervisors have low qualifications. They always play the roles of "referees" and "athletes" , when they work with executives. As a result, it is difficult to achieve the policy goals. For example, the fake and inferior commodities have been banned for a long time. However, the effect of that policy is nor ideal. The root cause is commodities counterfeiters, policy executives and policy supervisors have some common interests.

\section{6) Inadequate enthusiastic attitude and poor leadership} skill

The attitude of policy executives is one of the key factors of the effectiveness of public policy implementation. It is important for policy executives to treat policy implementation with enthusiasm. Different attitude leads us to take a completely different approach to the same thing and get different. The policy executives attitude towards policy always behave consciously or unconsciously. Those conscious or unconscious behaviour must influence policy implementation. 
The requisite qualifications of policy executives include integrity, optimism and fairness.

For leadership, the ability to execute government decisionmaking includes cognitive ability, thinking ability, analytical ability, organizing ability, communicative ability, command ability, coordinated ability, judgment and determination. The ability of policy execution is the performance of the executives in the process of policy implementation. Executives with high ability can quickly grasp the essence of policy. They can transform policy into action quickly and implement policy flexibly and effectively. For the various dilemmas that arise in the implementation of policy, it is possible for them to plan ahead and formulate policies in advance to prevent them from being affected.

\section{ADVICE FOR PREVENTING AND REMEDYING THE PUBLIC POLICY IMPLEMENTATION DEVIATION}

There is no universal best model for public policy implementation. Public policy implementation must base on different actional scenarios, identify effective execution patterns, establish the corresponding system and mechanism. In order to solve the problems existing in the process of public policy implementation, to ensure the effective implementation of public policy, and to achieve the public goals successfully, relevant measures must be taken accordingly. The major advice include: not only improve policy itself, such as formulate policy that have incorporation of adequate causal, make clear policy directives; allocate the financial and administrative rights of central government and local governments properly, but also ameliorate variables except policy, such as control the development of interest groups; make disadvantaged groups express their demands more easily; optimize the supervision mechanism of the public policy implementation.

\section{A. Make disadvantaged groups express their demands more easily}

Governments should make disadvantaged groups express their demands more easily, strengthen the citizens' awareness of interest expression. Improve the interest expression channels of various industries and departments. Expand the right of speech by improving the people's election system, petition system and hearing system. Governments ought to gradually institutionalize, standardize and normalize the expression of the interests of the masses.

\section{B. Optimize the supervision mechanism of the public policy implementation}

Governments should strengthen public supervision, think of innovative and sustainable ways to optimize the supervision mechanism continuously. Firstly, strengthen the independence of supervisory organs, formulate and improve the rules and regulation of the supervision of public policy implementation as soon as possible. Secondly, strengthen public supervision, explore the appropriate public supervision according to the actual situation of each region. Last but not least, give full play to the supervision of public opinion by media, focus on improving the comprehensive quality of journalists, improve the ability and standard of supervision.

\section{Improve the administrative accountability mechanism}

Intensify law enforcement efforts, increase the penalties for the mistake of policy implementation, punish those who responsible for making mistakes according to law and discipline. Firstly, establish special law and improve the legal guarantee of administrative accountability. Secondly, establish and improve performance appraisal system. Only the correct performance appraisal results can be relied upon. Last but not least, improve the information disclosure system and avoid administrative accountability operate through the back door.

\section{CONCLUSION}

To conclude, the harm of public policy implementation deviation must be given top priority. The framework of Paul A Sabatier and Daniel A. Mazmanian provides a dynamic and systematic perspective for the causes analysis of public policy enforcement deviation. Two aspects of policy, both policy itself and variables except policy, could be responsible for the deviation of public policy. And there are many indicators below these two aspects. These indicators must be paid due attention. So it is advised that a new effective mechanism should be provided to handle this situation. The central authority has to take concrete steps. For policy itself, (1) formulate policy that have incorporation of adequate causal; (2) make clear and unambigous policy directives; (3) allocate the financial and administrative rights of central government and local governments properly; (4) coordinate hierarchical integration within and among implementing institutions; (5) improve decision-rules of implementing agencies; (6) recruit appropriate policy enforcer; (7) provide formal access by outsiders as much as possible. Beside above, (1) Socio-economic conditions and technology should be paid due attention; (2)control the development of interest groups; (3) make disadvantaged groups express their demands more easily; (4)optimize the supervision mechanism of the public policy implementation; (5) improve the administrative accountability mechanism. And only by doing so can be public policy implementation deviation avoided utmost.

\section{REFERENCES}

[1] Donghang He, Fanbin Kong. The Chinese Experience of Public Policy Implementation [J]. Social Sciences in China, 2011(5): 61-79.

[2] Paul. A. Sabatier, Daniel A. Mazmanian. The Implementation of Public Policy: a Framework of Analysis [J]. Policy Studies Journal, 1980, 8(4) 541.

[3] Paul. A. Sabatier, Daniel A. Mazmanian. The Implementation of Public Policy: a Framework of Analysis [J]. Policy Studies Journal, 1980, 8(4) 542.

[4] Huafang Yin, Zhen Pan, Minghong Lu. The Relationship between Central Government and Local Government and Policy Execution: Take Foreign Industrial Policy as an Example [J]. Management World 2007(7): 22-36

[5] Masahiko Aoki, Jinglian Wu. From Authority to Democracy: Sustainable Political Economy [M]. Beijing: CITIC Press Group, 2008.187

[6] Christopher C. Hood. The Tools of Government [M]. Chatham: Chatham House, 1986, P.9. 